ARTIGO

\title{
Os estudos estratégicos como base reflexiva da defesa nacional
}

Strategic studies as the core discipline of national defense

DOMÍCIO PROENÇA JÚNIOR*

ÉRICO ESTEVES DUARTE**

Rev. Bras. Polit. Int. 50 (1): 29-46 [2007]

[T] he purpose of Strategic Studies is not so much to enlarge the debate, but rather to keep it focused.

Lawrence Freedman, "Indignation and Strategic Studies", 1984

\section{Introdução ${ }^{1}$}

A necessidade da produção de conhecimento científico em temas afins à defesa nacional e, mais amplamente, à política internacional, passa pela clareza do que sejam as contribuições emanadas de cada disciplina, ou, para cunhar um termo, das diversas interdisciplinas que se aproximam de tais temas. $\mathrm{O}$ foco deste artigo é a apresentação da experiência dos Estudos Estratégicos desde sua origem na década de 1940 através dos trabalhos que buscaram dar resposta aos diversos aspectos de sua razão de ser, propostas, dificuldades, resultados e cautelas. Pontua, sucessivamente, o porquê dos Estudos Estratégicos, a forma cíclica pela qual eles vêm sendo objetos de estudo, ensino e pesquisa, e o resultado capital sobre o papel da teoria da guerra de Clausewitz como cerne de seu desenvolvimento. Este percurso sustenta o conjunto de preocupações que se apresentam a guisa de conclusões.

\footnotetext{
* Professor do Programa de Engenharia de Produção de Produção da Coordenação dos Programas de Pósgraduação de Engenharia da Universidade Federal do Rio de Janeiro - UFRJ, membro do International Institute for Strategic Studies (domicio@centroin.com.br).

** Doutorando do Programa de Engenharia de Produção de Produção da Universidade Federal do Rio de Janeiro - UFRJ.

1 Este texto decorre do desenvolvimento do projeto de pesquisa "Tecnologia e Defesa" (CNPq) e da vigência da bolsa de produtividade em pesquisa concedida a Domício Proença Júnior e de doutorado concedida a Érico Esteves Duarte pelo CNPq. Seu conteúdo reflete ainda, em parte, o resultado de pesquisas e estudos anteriores com Eugenio Diniz, Salvador Ghelfi Raza, Mauro G. F. Mosqueira Gomes, Marco Cepik, Jacqueline Muniz, Tiago Cerqueira Campos, Wilson Lauria e Rafael Ávila, ainda que a responsabilidade por esta apresentação permaneça integralmente com os autores.
} 


\section{Porque}

Edward Earle escreveu em 1940 sobre "Defesa Nacional e Ciência Política”2, motivado pelo paradoxo perturbador entre a forte herança histórica militar dos EUA e os despreparo para guerra e apatia diante da queda da França e do sítio à Grã-Bretanha. Apesar dos EUA terem participado de diversas guerras, tanto a prática governamental como a academia eram incipientes em assuntos militares. Isso era especialmente perturbador nas ciências sociais e políticas, onde a falta de interesse sobre o "fenômeno bélico nas atividades humanas, "capaz de comandar nossas vidas, fortunas e destino"3 era incompreensível.

Esta era uma questão democrática fundamental, parte do preâmbulo da Constituição dos EUA, que listava a "defesa comum", como uma, e talvez $a$, função básica de um governo. A necessária subordinação dos militares aos civis ia além do entendimento de que a guerra era importante demais para ser abandonada aos generais, que sendo razoáveis nem mesmo desejavam tal mandato. A separação entre militares e civis não era apenas artificial, ela contrariava os princípios da democracia.

Da mesma forma, não há porque os civis não devam tomar para si os assuntos militares, que afetam a nação e cada indivíduo de maneira tão visceral. Afinal de contas, os problemas militares não pertencem ao reino do ocultismo, do supratemporal, ou do recôndito, porque o seu 'sigilo' diz respeito principalmente a questôes de material. Leigos bem informados podem analisar, criticar e contribuir de forma prática para a solução de problemas militares. Os dados objetivos sobre os quais edificar estudos sólidos tanto existem quanto se encontram amplamente disponíveis. De fato, éimperativo queleigos, especialmente professores universitários e estudiosos, se envolvam com o problema da defesa nacional, porque se não o fizerem condena-se ao fracasso qualquer esforço de rearmamento ou de guerra. ${ }^{4}$

Earle condenava a omissão da academia, da Universidade, que responde pela qualidade do conteúdo e pela oportunidade de sua contribuição no debate público. Esta omissão abria espaço a propagandistas, como Liddel Hart, cujas obras contribuíram para o colapso da França e arriscavam a sobrevivência da GrãBretanha. Este e outros propalavam equívocos popularescos que dogmatizam doutrinas, desqualificam a experiência, renegam a razão e desacreditam da possibilidade de vitória no contexto das guerras totais e insuflando a submissão diante da agressão. Eram derrotistas, mesmo quando afirmavam o contrário. Só tinham espaço porque o estudo da guerra na Universidade havia se tornado marginal, incidental, assistemático, marcado por militares escrevendo para militares ao invés de ser uma questão de cidadãos escrevendo para cidadãos.

2 EARLE, Edward M. National Defense: a program of Studies. Political Science Quarterly. New York, 55(4), 1940, p. 481-495.

3 EARLE. Op. cit., p. 482.

4 EARLE. Op. cit., p. 485. 
Essa era a tarefa primeira da academia. O debate político sobre estratégia e o uso da força não era apenas uma questão de tempos de guerra, mas inerente ao governo. A possibilidade dos tomadores de decisão terem claras as alternativas da ação governamental depende da Universidade, única capaz de coligir, sopesar e criticar fatos e alternativas, através da pesquisa, da educação, e do avanço conhecimento capazes de situar os assuntos militares como governamentais. A academia era ainda a fonte de cautelas capazes de contrarrestar perspectivas de falso senso comum, midiáticas. Por isso o abandono do tratamento dessas questôes na academia havia deixado os EUA reféns de medos, preconceitos e oportunismos, ao invés de poder se apoiar num acervo maduro e discutido de conhecimentos. Mas

[e]sse estado salutar de coisas não pode vir a ser produzido, pode-se afirmar, a menos de uma abordagem inteiramente nova para o problema da defesa nacional. O oficial profissional é incapaz de lidar com o problema porque, nos olhos do público e na mente do Congresso, ele representa seus próprios interesses. Em tempos de apatia ele é visto com suspeita, em tempos de crise com injusta reverência. Só o professor universitário, o estudioso, pode manter um estudo continuado, objetivo e documentado do problema. A experiência mostra que resultados comparáveis não podem ser esperados nem do público, nem do político, nem do governo e nem mesmo das forças armadas. Mais ainda, só o estudioso pode criar um vasto acervo de competência no campo. As pessoas a quem ele ensina e escreve hoje serão os eleitores, professores, oficiais da reserva e estadistas de amanhã. ${ }^{5}$

\section{Ciclos}

Bernard Brodie inaugurou o debate em "Estratégia como uma Ciência", enquadrnado o relacionamento necessário entre Estudos Estratégicos e as trajetórias formativas militares. O contexto particular de sua preocupação era o fato de que, nos EUA, a saída de militares de cargos importantes no pósguerra aquietava um juízo a seu ver inapropriado, de que a instituição militar extrapolava suas funções. A seu ver o verdadeiro problema, cujo enfrentamento era urgente, era que os militares não estivessem adequadamente preparados para atuar em estratégia. A evidência mais marcante disso era que a história militar e os pensadores considerados "clássicos", como Clausewitz, eram um arcabouço estranho aos militares e mesmo aos acadêmicos ditos especialistas.

Brodie entendia isto como decorrência da falta de formação acadêmica entre os militares. O que existia era uma educação militar baseada em princípios e máximas. Essas não formavam um aparato conceitual suficiente e se esgotavam em recomendações cujo conteúdo era apenas o do uso do bom senso ao redor de algumas questôes relevantes (por exemplo, a economia de esforços), mas não eram

5 EARLE. Op. cit., ênfases no original, p. 498.

6 BRODIE, Bernard. Strategy as a Science. World Politics. Baltimore, 1(4): 467-488, 1949. 
capazes de descrever, orientar ou aferir a ação. Pior, a questão era a difusão de uma adesão acrítica a esta forma de saber, que acabava por ignorar as recomendaçōes dos próprios autores de tais princípios, como a recomendação de Bonaparte sobre o estudo de campanhas concretas dos grandes comandantes.

Isto acabava contaminando o próprio entendimento do ofício militar, prejudicando tanto a dinâmica da evolução tática embutida na tecnologia quanto o aperfeiçoamento da "arte da guerra". Prendia-se ao credo do caráter insubstituível da experiência, e na falta de percepção a seus três limites intrínsecos: os limites do passado para o presente enquanto emulação; o sucesso ou fracasso como critério da verdade ou falsidade; e a ausência da capacidade de síntese analítica. Numa profissão que valorizava a ação, a decisão e a audácia, o problema da ausência de um critério de mérito cedia lugar, como falsa solução, ao dogma de qualquer decisão é melhor que nenhuma. Impunha a noção da padronização a entendimentos mais importante que os seus conteúdos. Deixava de lado que a questão não era de incerteza, mas de ignorância.

A passagem pelos colégios de Estado-Maior havia se tornado uma oportunidade perdida. Ao invés de uma transição educacional, passava a ser um interlúdio expositivo e superficial, intensos em atividades mas sem tempo nem motivação para a reflexão. $\mathrm{O}$ rumo de uma solução era evidente: os colégios de estado-maior tinham que migrar em direção a uma pós-graduação no sentido estrito. Mesmo os militares não sendo acadêmicos, eles não tinham como atuar em estratégia sem apreciar o que a academia lhes poderia dar. Que mais esta tarefa se somasse às suas responsabilidades era apenas mais uma instância que demonstrava como a carreira das armas não é fácil, exemplificando o tipo de demanda que um oficial superior e general têm que atender e superar. Brodie finalizava que a questão não era simplesmente de aproveitamento de talentos individuais; a questão era precisamente que só esta migração poderia edificar um entendimento disseminado que prometesse resultados.

Em "Através da Divisória Nuclear, Estudos Estratégicos Passado e Presente”, Colin S. Gray revelou a crise que estava oculta na perspectiva de Brodie: o postulado da irrelevância do pensamento estratégico pré-nuclear para as questóes presentes. Gray observou como as continuidades pré e pós 1945 eram mais relevantes que as descontinuidades, e que as categorias de problemas permaneceram: a utilidade da força, as alianças, as corridas de armamentos, as guerras limitadas, o controle de armamentos e a acomodação a novas tecnologias. Uma adesão puramente cosmética à questão histórica era insuficiente e enganosa.

Um novo olhar à questão da guerra nuclear reconhecia sua descontinuidade na letalidade de armamentos, mas desautorizava o início de uma "nova era" em que nada anterior tinha valor. E simplesmente negava que se pudesse reificar a guerra nuclear com um beco sem saída para a estratégia, como era o caso quando

7 GRAY, Colin S. Across the Nuclear Divide, Strategic Studies Past and Present. International Security. 2(1): 24-46, 1977. 
se afirmava que a dissuasão não era uma estratégia, por exemplo. Contestava a percepção da irrelevância do passado diante de uma 'Revolução nos Assuntos Militares', propondo um exercício contrafactual, o de descrever um mundo sem a arma nuclear. Este mundo teria os EUA e a URSS num enfrentamento transcontinental, marcado pela separação transcontinental de seus territórios e pelo papel dos EUA como única possibilidade de equilíbrio na Europa. Daí se teria a proliferação inicial de armamentos de longo alcance, como os bombardeios intercontinentais, e, na medida em que os custos destes fossem se revelando proibitivos, a aposta em alternativas econômicas de dissuasão: o gás dos nervos, por exemplo. Isto demonstrava que as superpotências não eram "super" por serem nucleares, eram nucleares por serem "super", removendo o determinismo tecnológico da situação internacional.

Gray remeteu o problema da constituição dos Estudos Estratégicos. Os Estudos Estratégicos seriam um desdobramento natural e necessário do empreendimento da cientificização da guerra durante a Segunda Guerra Mundial, em particular das diversas formas de otimização combatente e estratégica que associadas à Pesquisa Operacional. Esta vivência abriu os olhos das forças armadas para a existência de competências civis relevantes para seus propósitos e atividades, determinando um convívio e acesso crescente com as competências da sociedade. Tomando cada dez anos como uma geração nos Estudos Estratégicos, explicou como as primeiras duas gerações 1945-1956 e 1956-1965 ainda puderam tratar a arma nuclear como uma novidade. Em função da adesão à falsa idéia de que a arma nuclear era um divisor de águas, cada geração teve que admitir a falência dos resultados diretos da anterior, retornando a textos como os de Tucídides, Sun Tzu e Clausewitz para o reinício de sua própria construção intelectual.

Tratava-se mesmo de uma falência, que levava à autonomização das perspectivas de cada força singular e a um descaso para com um aparato conceitual íntegro. A falência ra a única explicação possível porque

[a] unidade essencial dos problemas estratégicos, que negam qualquer validade a estratégias terrestres, navais ou aéreas, foi claro reconhecida na prática de operações combinadas da Segunda Guerra Mundial ${ }^{8}$.

Gray explicou como esta lição foi afogada pelo tratamento nostálgico da Segunda Guerra Mundial, levando a uma afirmação da autarquia do presente. Mesmo contradita em diversas instâncias pela revelação de continuidades das perspectivas e iniciativas das décadas de 30 e 40 até adentro do mundo nuclear, sustentou-se a assertiva que o presente seria imune ao passado. Isto criou paradoxos com o qual o Ocidente aprendeu a conviver, adiando a consciência da inadequação de seu aparato conceitual. Como resultado, enraizou-se uma resistência real e afirmativa fosse à continuidade, fosse ao da teoria.

$8 \quad$ GRAY, op. cit., p. 38. 
Gray resgatou o papel ambíguo que foi dado à coletânea de Earle de 1943', mostrando como sua intenção de resgate dos últimos 450 anos de construção de estratégia como prova de sua continuidade e valor fora traída e utilizada contra o caminho que Earle apontara. Num arrastão arbitrário no uso da obra, Earle foi equivocadamente tratado como a lápide do pensamento estratégico pré-nuclear, e não como trampolim para o futuro da análise estratégica.

Esta recusa se afirmou ainda na fragmentação da própria estratégia, com perda de sua qualidade sinótica - passou-se a ter tantas estratégias quanto especialistas, do militar em diante, passando pelo analista estratégico, o historiador militar, o cientista social. Qualquer perspectiva de progresso em Estudos Estratégicos exigia uma (re)integração que conforontasse explicitamente esta situação.

Era útil recuperar Bernard Brodie que, mesmo partilhando o ponto de partida equivocado de que o pós-nuclear seria distintivo, fizera com clareza o diagnóstico da pobreza do trabalho teórico e suas consequiências diretas e pragmáticas: a quantificação desenraizada, a indigência intelectual estratégica e a má pratica militar.

Uma educação mais profunda e sistemática de uma nova geração de estrategistas e controladores de armamentos em história pré-nuclear de relevância pode ser justificado de diversas maneiras. Tal preparo deveria permitir aos estudantes distinguirem melhor o que é transiente do que é permanente; facilitar sua compreensão da estrutura dos problemas de política pública (com muitos casos mais passíveis de estudo), e deveria ajudá-los a reconhecer analogias e ilustraçóes históricas inapropriadas quando estas lhes fossem apresentadas. (...) Entre as virtudes do inquérito histórico está o fato de que seus resultados forçam políticos e analistas a confrontarem evidências que transcendem as fronteiras de suas experiências vividas - ainda que não se possa negar que cada geração irá interpretar a história de acordo com a sua própria experiência. ${ }^{10}$

Williamson Murray evidenciou como o processo complexo e, em alguma medida, enigmático, pelo qual passaram as escolas superiores das forças armadas dos EUA nos últimos 70 anos. "Sai Clausewitz, entra computador: cultura militar e hubris tecnológica" 11 dá testemunho do que lhe parecia ser - e de fato foi - o próximo movimento no ir e vir entre a afirmação do espaço da escola e da educação como posto e passagem associados a trajetórias exitosas de carreira e o seu uso como cemitério de carreiras esperando a aposentadoria. Isto corresponde à percepção lúcida de que

9 EARLE, Edward Mead, ed. Makers of Modern Strategy. Princeton: Princeton University Press, 1943 (reprint 1971).

10 GRAY 1997, nota 11, p. 46,

11 MURRAY, Williamson. Clausewitz out, computer in: military culture and technological hubris. The National Interest. Washington: Nixon Center, 1997. Disponível em: <www.nationalinterest.org> Acesso em: 31 out. 2006. 
Um dos aspectos importantes, mas pouco estudados, da história militar diz respeito às culturas institucionais pelas quais os corpos de oficiais apreendem os problemas dinâmicos e ambíguos da guerra e da paz. Tal cultura institucional molda a compreensão de alternativas estratégicas, operacionais e táticas que confrontam o soldado profissional, e implantam ainda as hipóteses mais amplas relativas à referência histórica que empresta sentido a estas alternativas. É um processo que depende de educação formal, aculturamento informacional e experiência prática.

Os eventos concretos no campo de batalha tem sido, tradicionalmente, o principal elemento de aferição da realidade sobre os entendimentos e hipóteses de qualquer cultura institucional militar, a despeito da ampla evidência de que as instituições militares, ocasionalmente, se revelam extraordinariamente relutantes em aprender com suas próprias experiências. E sendo difíceis de aprender no combate, quanto mais difícil ainda deve ser aprender as lições da guerra na paz, na ausência do mundo real, bruto, imprevisível e implacável da morte e destruição. Em conseqüência, é sem dúvida importante que, em tempo de paz, os profissionais militares trabalhem duro para formular o tipo correto de perguntas, gerando hipóteses realistas.

Em sua maior parte, porém, a história sugere que, em tempo de paz, as instituições militares formulem mais respostas que perguntas, esposando hipóteses que dizem mais respeito às suas próprias regióes de conforto intelectual do que da realidade ${ }^{12}$.

A geração de oficiais das décadas de trinta e quarenta, que lutou a Segunda Guerra Mundial, tinham uma formação acadêmica sólida, e entendiam a presença como alunos e docentes nas escolas superiores como uma etapa obrigatória e necessária. A direção de seus estudos pode ser apreendida pela afirmação do General George C. Marshall, de que seria impossível entender estratégia sem ter lido Tulcídides. O ponto a destacar é o quanto isso era algo compreensível e mesmo familiar para os oficiais de sua geração, e como se tornou incompreensível para algumas das geraçôes que os sucederam.

Essa situação mudaria nas próximas duas décadas, quando a gestão MacNamara promoveu uma adesão acrítica à quantificação como forma de entendimento e conduta da guerra e da defesa nacional. Neste processo, as escolas foram relegadas a postos de segunda, e o primado da ação e da experiência fez com que fosse uma moda abrir mão da passagem escolar quando ela era oferecida.

Conseqüentemente, o desastre militar do Vietnã na década de 1970 permitiu que a nova tradução do Da Guerra de Clausewitz por Michael Howard e Peter Paret viesse a ser tomada como a pedra fundamental do processo educacional militar dos EUA, instituindo um adensamento acadêmico em suas escolas pela incorporação de professores civis e práticas acadêmicas. Isto levou a um breve período em que os cursos militares tinham elevados padrōes de seleção e incluíam a possibilidade de programas doutorais afinados com os critérios universitários. Para Murray, o impacto dessa passagem é eloqüente, e se estende desde a reconfiguração

12 MURRAY, op. cit., $\$ 1-3$ do item "One of the Great". 
dos termos pelos quais se ganhou a Guerra Fria até a qualidade dos resultados, propriamente estratégicos, da Guerra do Golfo de 1990-1991.

É de alguma forma misteriosa como, em menos de uma década, se pudesse relatar uma falência quase completa destes espaços. Para Murray, o centro deste processo era a percepção equivocada de que a digitalização teria invalidado formas de guerra anteriores, tornando Clausewitz obsoleto. Isso correspondia à perspectiva de que a solução tecnológica era capaz de eliminar a necessidade de um entendimento mais amplo ou aprofundado da guerra.

O perigo da crença de que a tecnologia nos oferecerá dominância total no espaço de batalha (battlespace) e na política externa pelo próximo século não está na tecnologia ela mesma. A tecnologia pode, de fato, oferecer grande vantagem contra futuros oponentes. O que é perigoso sobre esta nova visão tecnocrática é a mesma coisa que era perigosa em sua versão anterior: é totalmente alienada do que os outros pensam, querem, e podem fazer. É precisamente porque nós Americanos temos uma longa história de superestimar nossa superioridade tecnológica e de subestimar a habilidade de nossos oponentes de por nossas vantagens em curto-circuito, que não podemos nos permitir esta hubris uma vez mais. É ainda por isso a causa do desespero diante dos sobretons que se podem ouvir sobre a iminente "revolução nos assuntos militares". (...)

Uma parte inerente da [atual] abordagem anti-Clausewitiziana é a crença de que o que a organização militar precisa é de mais dados quantificáveis, mais “informação". Uma vasta rede de sensores e computadores interligados seria capaz de reduzir a fricção inerente à equação militar a níveis toleráveis e controláveis. Mas o processamento de cada vez mais informação pode facilmente entupir as organizações militares com uma maré de dados indigeríveis. Pior ainda, as afirmativas presentes sobre dominância informacional perdem de vista a diferença essencial entre informação e conhecimento. Não precisávamos de mais informação em Pearl Harbor, e é duvidoso que precisemos de mais informação no futuro. O que necessitaremos no próximo século é um entendimento mais profundo do contexto político da guerra e o do conjunto muito diferente das hipóteses que podem pautar a ação de nossos oponentes. Necessitaremos de mais conhecimento sobre línguas estrangeiras, culturas, crenças religiosas, e acima de tudo história - que são precisamente os conhecimentos que os tecnocratas ignoram porque eles não podem ser quantificados. O que é mais importante na guerra é o que se passa na mente do nosso oponente. Essa é uma verdade bem ilustrada por uma cena da Guerra do Golfo. Quando um número de generais do Corpo de Fuzileiros Navais visitou um bunker [iraquiano] relativamente intacto e amplamente suprido, capturado pelas forças da Coalizão com um mínimo de baixas e um grande número de prisioneiros, um deles comentou num suspiro: "Graças a Deus os Norte-vietnamitas não estavam aqui”"13.

Betts evidenciou como as Universidades que possuíam departamentos ou linhas de pesquisa de estudo da guerra apresentariam os mesmos elementos cíclicos

13 MURRAY, op. cit., $\$ 11-13$ do item "The Gulf War". 
das academias militares. Em "Os Estudos Estratégicos devem sobreviver?"14, pergunta se o termo "Estudos Estratégicos" teria se tornado um equivalente acadêmico ao termo "União Soviética", devendo ser abandonado.

Sem dúvida, o próprio artigo é uma volta em algum ciclo, pois Betts recuperava as preocupaçōes de Earle e de Brodie sobre a utilidade do campo acadêmico para o estudo da estratégia e da dificuldade de sua preservação. Com o benefício destes, Betts contestava a escolha de se abrir mão de especialistas civis em questôes de defesa pós-Guerra Fria e, ainda, a inconseqüência da dinâmica corporativa acadêmica de restrição dos espaços acadêmicos para os Estudos Estratégicos diante do apetite e promessas dos assim chamados Estudos de Segurança. Um e outro emulavam, em termos civis, os equívocos militares de abandono de fundamentos no afă da novidade ou em prol de uma esperança. No caso acadêmico, isso se traduzia ainda na repulsa moralista quanto ao conhecimento relacionado à própria gramática dos meios da guerra, passando a tratá-la como uma "caixa preta", como se os aspectos políticos da guerra se resolvessem em si mesmos.

A primeira conseqüência disso era a própria perda de capacidade das disciplinas contemporâneas em compreender a guerra. Desprezar os meios por preconceitos de foco era abrir mão de alcançar o seu papel determinante nos resultados da política internacional. $\mathrm{O}$ resultado era uma tolerância à simples recusa de consideração dos aspectos materiais do uso de força, reificando de forma autárquica os panoramas políticos internacionais ou domésticos dos países. Isso correspondia ao abandono, puro e simples, do:

(...) problema Clausewitziano: como fazer da força um instrumento racional da política, ao invés de assassinato sem propósito - como integrar política e guerra. E isso exige a junção interdisciplinar da gramática militar e da lógica política, nos termos próprios de Clausewitz, um matrimônio que é freqüentemente pervertido na prática pelos que se identificam mais com uma metade da união do que a outra. Muitas vezes, soldados tem objeção a que a política permeie a guerra porque isso dá aos civis o direito de meter o bedelho em suas operaçôes. Muitos intelectuais recusam a que se dignifique a guerra como um instrumento político ou como uma prioridade acadêmica. Por todos esses motivos, a ciência política acabou se tornando o principal espaço acadêmico para o campo, e seu lugar nos assuntos militares é periodicamente questionado. Num campo eivado de debates sectários sobre estruturas amplas como o realismo, o liberalismo e suas variantes 'neo' como são as Relações Internacionais, as fronteiras enlameadas da estratégia acendem controvérsias. (...)

A maioria dos estudiosos de relações internacionais reconhece que a guerra é um problema importante, mas só estão interessados em seus antes e depois, não na guerra ela mesma - as causas e consequiências da guerra, mas não a sua conduta, que é relegada ao status de um epifenômeno ou como algo intelectual infantil. Os Estudos Estratégicos se interessam por todas as três fases porque elas são interdependentes;

14 BETTS, Richard K. Should Strategic Studies Survive?. World Politics. Baltimore, 90(1): p. 7-33, 1997. 
conduta torna-se causa quando os mecanismos da violência moldam as decisóes sobre o seu uso político. Fica impossível compreender os impulsos e escolha da dimensão política da guerra ou da paz sem compreender as restriçōes e oportunidades da dimensão militar. São as opçôes de como fazer a guerra que afetam se fazer-se a guerra, quem ganha e quem deveria ganhar, e que desta maneira conformam o mundo do pós-guerra. ${ }^{15}$

Betts afirmava que o compromisso gerado pelo reconhecimento de que a guerra é um assunto importante de mais para ser deixado aos generais, que ecoa desde Lloyd George e Clemenceau, tem sido negligenciado pelos próprios especialistas civis. Acabou produzindo a situação em decisões são postas diante de civis ignorantes da guerra, desprovidos de aparato capaz de lidar com o conteúdo militar, ou são empurradas a militares que têm que decidir sozinhos, sem maior capacidade de avaliar as conseqüências políticas.

Se a estratégia deve integrar política e operações, tem que ser concebida não apenas por militares politicamente alertas, mas por civis militarmente alertas. Quaisquer destes deixam terceiros na política ou na academia desconfortáveis. Ironicamente, muitos estudiosos que respaldam um forte controle civil sobre os militares acabam relutantes quando se trata de dar substância a este controle pela promoção de estudos estratégicos civis.

Amadores não deveriam controlar o que não compreendem, especialmente em assuntos em que há legióes de vidas em jogo. $\mathrm{E}$ ainda assim críticos acadêmicos compartilham do ceticismo militar quanto à atenção intelectual aos detalhes de operaçôes militares (ainda que por motivos diferentes). ${ }^{16}$

Betts concede que este é um fenômeno cíclico, observando que estaríamos num terceiro movimento nesta direção desde a Segunda Guerra Mundial. Aponta que o problema essencial da relação civil-militar e das Universidades pode ser fundamentalmente generacional, talvez em razão da juventude das instituições civis em sociedades democráticas que lidam com a guerra. Mas é preciso uma medida de cautela diante de militantismos que aspiram a conformar o entendimento em função de desejos piedosos quanto ao futuro.

A guerra sempre foi um fenômeno essencial na política mundial. Não há nada errado em se afirmar que ela está minguando, contanto que estas proposições (que já foram popularizadas e em seguida desacreditadas três vezes no último século) não se arvorem em remover o assunto da lista dos temas de maior prioridade da agenda. Se a guerra ficar obsoleta, o esforço intelectual perdido em se continuar estudando o tema terá sido um custo pequeno. Se isto não vier a ocorrer, e se estas pesquisas tiverem qualquer impacto útil, então as gerações futuras se alegrarão que tenhamos mantido nossa pólvora intelectual seca. ${ }^{17}$

15 BETTS, op. cit., p. 7-9.

16 BETTS, op. cit., ênfases no original, p. 25-26.

17 BETTS, op. cit., p. 33. 


\section{Clausewitz}

Com tudo o que se já escreveu, e escreve, sobre a obsolescência ou a imoralidade dos trabalhos de Clausewitz, não há como evitar o resultado mais incisivo de seus críticos mais sinceros ou selvagens. Em qualquer momento dado, é comum que se afirme a Teoria da Guerra como uma das diversas possibilidades de igual potencial do entendimento da guerra. Isso é usualmente acompanhado da atribuição da qualidade de "clássico", que em muitas disciplinas significa que não deve ser lido, embora possa ser citado em epígrafes. Em outras tradições, uma obra centenária tem estar, necessariamente, obsoleta, e se busca o que quer que seja a produção dos últimos cinco anos em periódicos como sendo aprioristicamente superiores. Há ainda quem discorde do mérito por não querer encarar os resultados. No entanto, assim que se tem a perspectiva de ter formulado algo novo sobre a guerra cai a máscara de equanimidade para com os proponentes antes listados como alternativas. Porque o pleito de novidade descobre que a interlocução com a Teoria da Guerra é não apenas necessária, mas, num reconhecimento tardio e sincero, descobre que só a interlocução com Clausewitz pode vir a ser suficiente.

Em "Educação, Política e Guerra na Vida de Clausewitz"18, Paret realizou uma dessas passagens que reconfigura um campo do saber. Criticou de maneira cabal a literatura especializada de seu tempo considerando as fontes em inglês, alemão e francês, concluindo pela insustentabilidade das interpretações vigentes, marcadas pela fragmentação dos aspectos que compóe o título de seu artigo. Acusou, ainda, os que deliberadamente abandonavam a integridade do estudioso, político e soldado, privilegiando um ou outro aspecto como dispositivo retórico de críticas, quando não como erros de partida irrecuperáveis.

Paret delineou os termos da real dimensão de Clausewitz e de sua obra, refletindo um esforço original com acesso ao conteúdo total de seus escritos. É com base nessa reapreciação integral que Paret propôs que o ideal que eleva a reflexão intelectual de Clausewitz a uma qualidade superior é seu entendimento da educação como o germe transformador do indivíduo, do Estado e da guerra. Essa é a posição intelectual que acomoda toda a gama de suas considerações políticas, militares e éticas.

É difícil separar a apreciação valorativa da justeza destas questôes intelectuais de seu valor prático de maximizar o poder prussiano. O próprio Clausewitz não se preocupava com tal distinção: identificou as possibilidades de melhoria e incremento do conteúdo de sua profissão, a conduta da guerra, de sua classe, a militar, e do futuro de seu país no contexto, e com o benefício, da transformação política e social que se difundia pela Europa. Não há, portanto, contradição que fosse um inimigo implacável de Bonaparte e da Revolução e, ao mesmo tempo, um defensor convicto, tanto apaixonado quanto intelectual, da maior participação

18 PARET, Peter. Education, Politics, and War in the Life of Clausewitz. Journal of History of Ideas. Philadelphia, 29(3): 394-308. 
popular. O centro dessa última era a educação, que passaria a ser objeto de política pública por ser capaz de fazer do súdito, um cidadão e, portanto, um soldado animado pelo amor à pátria e não pelo medo da punição.

$\mathrm{O}$ conceito de educação de Clausewitz afirmava um relacionamento recíproco entre individuo e sociedade. Por um lado, o indivíduo estaria sujeito à educação política em termos de torná-lo consciente e apto a contribuir para a sociedade. Por outro lado, a sociedade estaria inclinada a formar a personalidade e a maturidade particular de cada indivíduo, permitindo o livre desenvolvimento de suas potencialidades. Clausewitz, beneficiário e partícipe consciente do processo de reforma da educação prussiana na virada dos Séculos XVIII para XIX, compreendia que esta havia se transformado numa questão capital. Como um dos principais ativistas do movimento reformador, condicionou a própria possibilidade de sobrevivência da Prússia à reforma, que desenvolvesse uma conjunção salutar entre soberano, governo e povo. Foi tal reforma que, mesmo incompleta, gerou a força necessária para as Guerras de Libertação da Prússia (1813-1814).

Vencida a guerra, Clausewitz dedicou-se à elaboração de um arcabouço conceitual que contribuísse para a conclusão de tal reforma democrática explicando a conduta da guerra.

Da Guerra é uma tentativa de descobrir os princípios, forças e tendências que orientam a guerra, de compreender as funções da violência nos relacionamentos entre os Estados, e especular sobre o seu uso racional e bem-sucedido. Só combinando o universal com o específico é que Clausewitz podia aspirar a sequer dar início a tal empreendimento. Não era apenas a guerra dos primeiros anos do Século XIX que servia como seu objeto de estudo, mas a guerra desde o início dos tempos. Sua experiência pessoal e conhecimento histórico tinham assim que ser abstraídos, com as generalidades daí resultantes, sendo objeto de análise lógica para seus desenvolvimento e refinamento. Possivelmente em função deste objetivo universal, suas opiniōes sobre assuntos políticos contemporâneo mal são mencionadas no curso de seus argumentos; por outro lado, ele se apóia amplamente em seus estudos históricos.

Clausewitz tinha pena dos homens práticos que só se interessavam por teorias que lhes dissessem o que fazer. Não cabia à teoria, ele escreveu, dar fórmulas para a ação; no máximo a teoria podia treinar e fortalecer o juízo de quem agisse. A pureza deste entendimento não foi comprometida, mas recebeu uma nota realista que é típica do pensamento de Clausewitz, pelo seu argumento de que quanto mais uma teoria se aproxima da meta do completo entendimento, mais ela afastava da condição objetiva de conhecimento para a condição subjetiva de habilidade. $\mathrm{O}$ inquérito especulativo rigoroso, emanado da visão mais ampla possível do problema, podia desta forma acomodar o seu interesse no concreto, sem sucumbir a demandas imediatas que haviam limitado a permanência de todas as teorias militares anteriores. $\mathrm{O}$ resultado era um trabalho de validade geral. Apoiava-se em algumas leis básicas: que a violência era a essência da guerra; que a violência não admite modificação lógica; que o conceito absoluto de guerra é sempre modificado pelas forças do mundo real. Estes princípios eram suplementados pelas análises dos propósitos de guerra e os meios pelos quais 
estes propósitos podiam ser obtidos - 'a guerra é um instrumento político' é uma conclusão; 'cada sociedade determina suas próprias formas de violência' é outra - e pela discussão dos fatores morais e psicológicos envolvidos no ato de guerrear. ${ }^{19}$

O melhor enquadramento para que se possa apreciar o artigo de Gray, "Quem manda na parada é Clausewitz, valeu? - o futuro é o passado com GPS" ${ }^{20}$, é o seu contexto. Ele resultou do convite da British International Studies Association para a um diagnóstico do campo do Estudos Estratégicos em número especial da Review of International Studies. Trata-se de uma apresentação sem meias medidas, provocativa como o seu título revela. Seu centro é a afirmação de que existem obras clássicas, essenciais, "que colocaram as grandes coisas de maneira suficientemente correta" 21 .

Gray situa a discussão da necessidade e preeminência de Clausewitz em termos da utilidade política do saber do uso de força. Entende o valor de sua teoria a partir da perspectiva de que uma teorização digna desse nome se confronta e busca explicar a realidade. Nisso, expressa o juízo bem-humorado de que ao assumir-se no campo dos Estudos Estratégicos, é obrigado a reconhecer que

[s]abe-se que se têm problemas como estudioso quanto uma questão tão corriqueira quanto o nome de seu campo de estudos, e de sua especialidade, trazem consigo bagagens indesejadas. Proponho lidar com este fato ignorando-o. $\mathrm{O}$ texto se refere às relações internacionais, política internacional, estudos internacionais e política mundial sem temor, favor ou significado subjacente. Com relação ao canto particular no amplo campo assim indicado, sou mais rigoroso. Referências em meu texto a estudos, teoria, ou história "estratégica" indicam assuntos conexos de maneira direta com o uso da força. De quando em vez, para sinalizar minha liberalidade de espírito e perspectiva genuinamente holística, refiro-me a estudos "de segurança". Mas que conste o registro de meu voto subscrevendo a posição de que o conceito de estudos de "segurança" seria inclusivo até a impossibilidade de sua execução. Estudar a "segurança" exigiria o estudo de tudo, um fato que se materializaria no estudo inteiramente sem foco sobre coisa alguma em particular. ${ }^{22}$

As perspectivas de uma paz duradoura eram tão vivas nas vésperas das Guerras Napoleônicas quanto nas das Primeira e Segunda Guerra Mundiais. É necessário impedir que esforços moralizantes venham querer maquiar o uso da força vestindoo com outras roupagens, afirmando causalidades distintas da política, esferas de saber distintas da estratégia, como as intervençōes humanitárias ou as Missões de Paz. Isso só leva a erros, e erros usualmente produzem tragédias.

19 PARET, op. cit., p. 406-407.

20 GRAY, Colin S. Clausewitz Rules, OK? - the future is the past with GPS. Review of International Studies. Special: 162-182, 1999.

21 GRAY, op. cit., p. 162.

22 GRAY, op. cit., p. 161, nota 3. 
Afirmando a centralidade dos Estudos Estratégicos para qualquer perspectiva conseqüente dos estudos internacionais, aponta sua capacidade explicativa como argumento suficiente para dar-lhes atualidade. Destaca, ainda, ciente dos pleitos contemporâneos, como se tratam de realidades que são factuais e não socialmente construídas. Reconhecer as falhas dos Estudos Estratégicos, de Clausewitz, não significa deixar de afirmar o seu valor perene. Qualificando a ocorrência, freqüência e gravidade dos "maus tempos" como contingentes à situação particular de um povo ou país, ainda assim o uso da força se põe. É incisivo ao apontar como é

[p]ara obter um desempenho superior para estes 'maus tempos' quando a ameaça ou o uso concreto de força se torna uma preocupação dominante, os escritos de um General-de-Brigada Prussiano, publicados a 167 anos atrás são um fonte destacada de inspiração. No Da Guerra Clausewitz está certo o bastante sobre o essencial de seu assunto. De fato, ele é tão correto que não há competidor plausível entre os demais teóricos de estratégia. A analogia entre Clausewitz para os Estudos Estratégicos e Aron e Morgenthau para as Relações Internacionais não é menos válida por ser amplamente indesejável para muitos estudiosos contemporâneos. Da mesma forma que Clausewitz explica a estratégia para todos os tempos, Aron e Morgenthau informa seus leitores da maior parte, e possivelmente de tudo, que eles realmente precisam saber. (...) claro que o Da Guerra de Clausewitz tem seus limites, como os tem o Paz e Guerra de Aron e o Paz entre as Naçōes de Morgenthau. No entanto, não se busca a perfeição, mas sim explicaçōes suficientes para o mal-comportamento humano na esfera da política mundial. ${ }^{23}$

\section{Preocupações}

Em 2005, Hew Strachan soou o alarme ao documentar a situação atual como sendo a de perda do significado da estratégia ${ }^{24}$. Seu diagnóstico é que se perdeu de vista o que é, e para que serve, a teoria que sustenta o entendimento e a ação estratégica. Isso é especialmente trágico quando esta perda parece advir de um processo difuso que destruiu o conteúdo do termo "estratégia", reduzindo-o a um conjunto de platitudes e banalidades.

Isso reflete uma tolerância irresponsavelmente superficial, que toma usos claramente retóricos do idioma e mesmo esforços deliberadamente propagandísticos como propostas de categorias ou conceitos. Reflete uma arrogância pseudopragmática diante da teoria que acaba por destruí-la através da sucessão de tentativas ad hoc de re-definiçōes da guerra, que são a tentativa de redescobrir termos originais Clausewitzianos ao mesmo tempo em que os recusa de partida. Assim, a clareza do que sejam as dimensões política, tática e estratégica da guerra como um fenômeno acaba obscurecida por meias medidas e emendas, quando não por modismos, marketing ou pela sonoridade de uma determinada formulação.

23 GRAY, op. cit., p. 179-180.

24 STRACHAN, Hew. Lost Meaning of Strategy. Survival. London, 47(3): 33-54, 2005. 
Ao longo do Século XX, sucederam-se 'grande estratégia', 'estratégia total', níveis de estratégia (militar, naval, aérea, aeroespacial, industrial, operacional, etc.) e não-estratégia. Admitiu-se até mesmo expressões mais ou menos doutrinantes da "arte" ou "ação" operacionais, que acabam sendo pouco mais que um novo capítulo na luta por autonomia militar. Mesmo acadêmicos vêm ceedendo à ambição de uma expansão tal da estratégia que chegam a aceitar que se abandonem os Estudos Estratégicos pelos Estudos de Segurança, cujo resultado final foi o de "ao tentarem ser inclusivos, acabarem sendo nada" 25 .

O rumo do reparo, aponta Strachan, é razoavelmente óbvio: só o estudo de história pode colocar teorias em seus contextos, e só o retorno à fonte teórica no rigor de seu conteúdo, com o benefício da crítica, pode reedificar a estratégia. Aqui o perigo é o exílio, por dinâmicas corporativas militares e acadêmicas, da estratégia a um tipo de consideração histórica.

Mas a estratégia não é uma questão para historiadores. Diz respeito a todos nós. A estratégia diz respeito à guerra e à sua conduta, e se a abandonamos, abrimos mão da ferramenta que nos ajuda a definir, moldar e compreender a guerra. (...) [Uma] verdade fundamental mas pouco apreciada [é] que a guerra tem sua própria natureza primordial, independentemente de sua ambientação política ou social. Mas as potências do Ocidente conspiraram, inconscientemente, para o processo pelo qual a guerra uma vez mais passa a ser compreendida apenas em seus termos primitivos. Arrancou-se a guerra de seu contexto político. (....) Mesmo Estados envolvidos de facto numa guerra não mais a declaram, receosos de infringirem o Direito Internacional. Paradoxalmente, assim, o Direito Internacional desregulamentou a guerra. ${ }^{26}$

Tal desregulamentação acena com as mais graves conseqüências: a impropriedade do recurso ao uso de força para os fins daqueles mesmos que o consideram. Uma guerra sem regulação se arrisca, a todo o momento, a ser uma guerra sem controle, pura destruição infrutífera e inconseqüente.

O Estado tem, portanto, um interesse em se re-apropriar do controle e da direção da guerra. E esse é o propósito da estratégia. A estratégia existe para que a guerra seja útil ao Estado, para que ele possa, se necessário, usar de força para atingir objetivos políticos. Uma das razóes pelas quais estamos inseguros sobre o que é a guerra é porque estamos inseguros sobre o que é, ou não é, estratégia. Não é política pública; não é política; não é diplomacia. Relaciona-se com elas, mas não as substitui. Definições abrangentes de estratégia podem ter ajudado durante a Guerra Fria, mas este foi - ironicamente - um conflito potencial da magnitude das duas guerras mundiais e uma era de comparativa paz entre as grandes potências. Vivemos agora numa era em que se percebe uma disposição pronunciada de parte dos Estados Unidos e do Reino Unido para irem à guerra. As guerras de hoje não são como as duas guerras

25 STRACHAN, op. cit., p. 47.

26 STRACHAN, op. cit., p. 48. 
mundiais, cuja escala deu margem às noções de grande estratégia. Naquela ocasião, grandes idéias ajudaram a lidar com grandes problemas. Mas hoje tais conceitos, aplicados de maneira frouxa, roubam as guerras localizadas diante do mundo de escala e definição. As ameaças são infladas e se tornam menos gerenciáveis pelo uso de um vocabulário que é impreciso. A "guerra contra o terror" é o caso em tela. É compreensível que, depois do choque de 11 de Setembro, os EUA tenham maximizado o problema, tanto em termos do ataque original (que poderia ter sido tratado como crime, não como guerra) quanto em termos das respostas necessárias para lidar com a ameaça subseqüente. Os EUA não souberam relacionar meios a metas (no sentido militar) e a seus objetivos (no sentido político). Abandonaram a estratégia. Usaram de palavras como prevenção e preempção, conceitos derivados da estratégia, mas sem contexto. Tornaram-se assim não fundamentos de ação militar, mas diretrizes de política externa. ${ }^{27}$

Gray pode, uma vez mais, ter apontado para o que é o centro da questão, confrontando a expectativa de que o Século XXI seria um idílio pacífico em contraste com o Século XX. Outro Século Sangrento ${ }^{28}$ comunica o seu prognóstico. Reduzir esta visão aos desdobramentos do 11 de Setembro é perder de vista a amplitude e a prudência que orientam a apresentação do contexto da guerra. A questão é a evolução do sistema internacional, dito de maneira clara, dos processos pelos quais a atual posição dos EUA será mantida ou desafiada.

Isso incorpora e reflete a diversidade de interesses regionais e mesmo locais. Contra a complacência e arrogância do Ocidente, alerta para a existência de visões de mundo distintas, que admite questões propriamente culturais e política quanto a metas e valores, que assegura o surgimento de formas alternativas, simétricas ou assimétricas, de construção e uso dos instrumentos de poder e de guerra. São esses os elementos que tem que ser considerados na gestão do equilíbrio de forças e poderes em função dos interesses envolvidos, e não a reprodução de versões do Ocidente, de suas formas de democracia e mercado como um dever-ser universal e consensual. Daí sua preocupação, já que

(...) é difícil fazer bem estratégia. Mas ainda, alguns países parece mal "fazer" estratégia. Os Estados Unidos da América são principal exemplo de um país que raramente "faz" estratégia. A comunidade de defesa dos EUA produz muitos livros e estudos, e realiza muitas conferências em homenagem à estratégia. Mas na prática é seu hábito lutar taticamente, e agora operacionalmente, e não estrategicamente. É dizer, aplica-se força, mas com uma direção política incipiente. Estratégia diz respeito a ameaçar ou aplicar a força com um propósito dado pelos fins da política. Neste mister, quando convidada, a estratégia é o controle vital do comportamento militar. Deveria determinar quanta força se empregar tanto quanto como empregála. Assim como a direção política, a estratégia é despida de valores. Quando atende

27 STRACHAN, op. cit., p. 49-50.

28 GRAY, Colin S. Another Bloody Century: future warfare. London: Weidenfeld \& Nichols, 2006. 
a uma direção política ambiciosa e expansiva, a estratégia também deve sê-lo. Mas a estratégia deveria sempre manter o controle dos rumos da guerra. Mesmo Estados que não conseguem compreender estratégia, ou que persistem, para além de uma educação superficial, em afrontar o saber estratégico, irão descobrir que seu comportamento militar tem efeito estratégico.

A estratégia pode ser concebida explicitamente para os fins da dissuasão. Nestes casos objetiva, sem dúvida, controlar a ocorrência da guerra. O grau com que a estratégia de fato controla a guerra depende das circunstâncias locais, especialmente as circunstâncias culturais. ${ }^{29}$

Dar conta do desafio estratégico não acontece automaticamente. Demanda um equilíbrio, um sistema de responsabilização e contrapesos entre as organizações militares, o governo e a academia. Se cada um destes atores for seguir suas próprias inclinações e tendências, então o resultado pode ser um novo divórcio na reflexão estratégica, como foi o caso dos EUA no Vietnã. A questão não é pedante, ou "acadêmica" no sentido pejorativo de diversas tradições anti-intelectuais. Diz respeito ao risco de uma dessas tragédias que macula décadas ou mesmo do desamparo nacional diante do bélico. Gray dá eco presente a preocupação de Earle e de Brodie, de Paret e Betts que corresponde, em termos amplos, ao problema da democracia diante da necessidade de compreender e usar do bélico. Essa é a compreensão dos Estudos Estratégicos em sua plenitude e razão de ser, assumindo a tarefa de dar conta do mérito das causas, condutas e conseqüências do bélico, que os revela como a base reflexiva da Defesa Nacional.

Recebido em 20 de novembro de 2007 Aprovado em 4 de abril de 2007

\section{Resumo}

O artigo pontua a trajetória dos Estudos Estratégicos desde sua origem para embasar o pleito de sua centralidade em temas afins à Defesa Nacional. Discute o porquê de tal 'interdisciplina', a forma cíclica pela qual eles vêm sendo objetos de estudo, ensino e pesquisa em estabelecimentos civis e militares e o resultado capital da centralidade da Teoria da Guerra de Clausewitz para seu desenvolvimento. Apresenta, à guisa de conclusões, um conjunto de preocupações sobre a atualidade dos Estudos Estratégicos.

\section{Abstract}

The article discusses Strategic Studies from its beginnings in support of the plea of its central role in National Defense affairs. It discusses why such an 'interdiscipline' came into being, the cyclical character of its application in civilian and military education and research and

29 GRAY, op. cit., p. 364. 


\author{
DOMÍCIO PROENÇA JÚNIOR | ÉRICO ESTEVES DUARTE
}

the capital role of Clausewitz's Theory of War in its development. It shares, as conclusions, some concerns about the current state of Strategic Studies.

Palavras-chave: Defesa Nacional, Estudos Estratégicos, Educação Militar, Educação de Pós-Graduação, Clausewitz, Teoria da Guerra, Política Internacional.

Key words: National Defense, Strategic Studies, Military Education, Graduate Education, Clausewitz, Theory of War, International Politics. 